\title{
The application of Nordic walking in the treatment hypertension and obesity
}

\author{
CEZARY KUCIO ${ }^{1,2, A, c-G}$, DOMINIKA NARLOCH ${ }^{1, A-D, F}$, EWA KUCIO ${ }^{1, A, c-F}, J O ́ Z E F ~ K U R E K{ }^{2, D, E, ~}$
}

${ }^{1}$ The Department of Physiotherapy at the Jerzy Kukuczka's Academy of Physical Education in Katowice, Poland

2 The Multidisciplinary Hospital in Jaworzno, Poland

A - Study Design, B - Data Collection, C - Statistical Analysis, D - Data Interpretation, E - Manuscript Preparation, F - Literature Search, G - Funds Collection

Summary Background. Increasing physical activity is a widely recognized method of prevention and treatment of hypertension and obesity.

Objectives. The aim of the following study was to assess the results of application of Nordic walking in the treatment of patients with hypertension and obesity.

Material and methods. Participating in the study were 30 overweight or obese men with hypertension, undergoing pharmacological treatment, randomly assigned to one of the two study groups. The first group performed Nordic walking training for 4 weeks. The second group underwent pharmacological treatment only. The value of blood pressure measured with a 24-hour AMBP monitoring device, exercise tolerance based on the duration and value of the metabolic equivalent during the exercise test, body mass and BMI value, as well as total cholesterol, LDL, HDL and triglyceride values, were measured before and after the study.

Results. The results of the study demonstrated the fact that the application of Nordic walking over the course of 4 weeks did not cause significant changes as far as the value of blood pressure. However, the training led to increased exercise tolerance, a reduced body mass and BMI value, as well as lowered triglyceride and total cholesterol levels. There were no cases of discontinuation of the training due to unwanted effects or symptoms.

Conclusions. The 4-week period of Nordic walking training did not result in the lowering of blood pressure in patients with hypertension. However, Nordic walking training did result in improved exercise tolerance, decreased body mass, as well as reduced metabolic risk factors for cardiovascular disease.

Key words: Nordic walking training, hypertension.

Kucio C, Narloch D, Kucio E, Kurek J. The application of Nordic walking in the treatment hypertension and obesity. Fam Med Prim Care Rev 2017; 19(2): 144-148, doi: https://doi.org/10.5114/fmpcr.2017.67870.

\section{Background}

The positive effect of increased physical activity in relation to blood pressure values demonstrated by research constituted a basis for physical training to be recommended as a means of prevention and non-pharmacological treatment of hypertension [1].

Nordic walking (NW) is a rapidly developing and is an increasingly popular form of physical activity in Northern Europe, especially in Scandinavia, Germany and Poland. The simplicity and ease of the march enables persons of different ages and physical conditions to partake in the sport. During Nordic walking, $90 \%$ of the human muscles are involved [2].

It is to be accentuated, however, that NW is mostly conducted outdoors; therefore, in contrast to workouts performed in stationary conditions, the patient cannot be monitored on a constant basis (ECG monitoring, blood pressure values, heart activity). Moreover, the patient is also affected by meteorological conditions (air temperature, wind) and the roughness of the ground. Therefore, patients with cardiovascular disease ought to be carefully evaluated in order to exclude possible contraindications and avoid potential unwanted effects during NW training [3].

Due to the conditions mentioned above, there have been few studies on the topic of the application of Nordic walking in the treatment of patients with cardiovascular disease [4-7].

\section{Material and methods}

The subjects were 30 overweight or obese men aged 47 to 66 , with pharmacologically treated hypertension, who granted their willful consent to participate in the study. The permission of the local Bioethics Committee was obtained.

Inclusion and exclusion criteria were applied to the patients partaking in the study with the aim of creating a homogenous study group and assuring the safety of patients during NW training.

The inclusion criteria were as follows:

1) men diagnosed with hypertension who were overweight or with obesity measured,

2) patients were treated pharmacologically, and the resting heart rate of the patients did not exceed a value of $139 / 89 \mathrm{~mm} \mathrm{Hg}$,

3) patients were allowed by a physician to partake in NW training,

4) willful consent to participate in the study.

The exclusion criteria consisted of the following:

1) unstable angina and chronic heart failure,

2) hemodynamically significant aortic stenosis,

3) acute myocarditis or pericarditis,

4) uncontrolled hypertension,

5) thromboembolism,

6) refusal to participate in the study.

The criteria for aborting NW training were: exacerbation of ischaemic heart disease or chronic heart failure, a blood pressure of a value greater than $140 / 90 \mathrm{~mm} \mathrm{Hg}$ pre-workout or greater than $180 / 100 \mathrm{~mm} \mathrm{Hg} 10$ minutes following the workout or the lowering of blood pressure below $120 / 80 \mathrm{~mm} \mathrm{Hg}$ following the workout, as well as the decision of the supervising physician. 
The first stage consisted of a basic medical examination, as well as additional evaluations, such as: resting ECG test, exercise test on a treadmill, echocardiography, 24-hour AMBP blood pressure test, laboratory tests (total cholesterol, HDL, LDL and triglyceride levels). All participants were qualified for the second stage of the study, in which the patients were divided into two groups.

The first group consisted of 15 men who undertook NW training along with receiving standard pharmacological treatment. NW training was conducted 5 times a week for a period of 4 weeks. Each exercise session consisted of a 10-minute warm-up. During the first week, the participants performed a march at the speed of $3 \mathrm{~km} / \mathrm{h}$ for a duration of 30 minutes. During weeks $2-4$, the speed of the march was raised to $5 \mathrm{~km} / \mathrm{h}$, and the duration of the workout was raised to 40 minutes. During NW training, the patients reached about $40-70 \%$ of maximum heart rate. Target heart rates were obtained using the Karvonen formula: $\left[\left(\mathrm{HR}_{\max }-\mathrm{HR}_{\text {rest }}\right) \times(0.5\right.$ to 0.8$\left.)\right]+\mathrm{HR}_{\text {rest }}$. The participants were trained in the NW gait method. During the whole process of evaluation, the subjects reported to a supervising physiotherapist pre- and post-workout about the occurrence of the following symptoms: stenocardial symptoms, exertional dyspnea, dizziness and fatigue. The patients underwent blood pressure and heart rate tests during the course of the study.

The control group consisted of 15 patients who received pharmacological treatment only. Control group patients, as well as NW group patients, regularly reported to the supervising physiotherapist (via telephone calls) about the occurrence of unwanted symptoms similar to the aforementioned.

After the evaluation was finished, every patient partaking in the study underwent a 24-hour AMBP test, exercise test and laboratory tests.

Additionally, body mass measurements of each participant were taken at the beginning of the study, and Body Mass Index (BMI) was calculated.

The following methods and research tools were used:

1) A 24-hour AMBP test registered with the use of Boso Tm 2430 (Bosch\&Sohn) device. Medial blood pressure values (systolic, diastolic and mean arterial pressure) measured daily, as well as during day time (6.30 am $10 \mathrm{pm})$ and night time $(10 \mathrm{pm}-6.30 \mathrm{am})$, were used for analysis of the obtained results in accordance with ESH/ESC standards [1];

2) Exercise tolerance was evaluated through an exercise test conducted on a treadmill with the use of the CardioTEST Alfa System B612 v.0.001 (ASPEL) set. The evaluation was conducted using the Bruce Protocol and was in accordance with the applied standards. Metabolic equivalent (MET), as well as the duration time of the exercise test, were taken into consideration;

3) Laboratory tests regarding total cholesterol, HDL, LDL and triglyceride levels were conducted in a hospital laboratory with the use of widely approved methods;

4) Anthropometric indicators, such as: body mass and height, were measured with clinic scales. BMI was calculated in accordance with the following equation: $\mathrm{BMI}=$ body mass in $\mathrm{kg} /$ height in $\mathrm{m}^{2}$.

Statistica 10 Software was used in order to perform statistical analysis. Arithmetic mean and standard deviation were calculated for measurable variables. All quantitative-type variables were evaluated using the Shapiro-Wilk test in order to determine the type of distribution. For comparison of the results achieved by the two study groups, the non-parametric Whitney-Mann test for independent variables was used. In order to compare the before and after results in respective groups, the Wilcoxon test for independent variables was used. A level of $\alpha=$ 0.05 was presupposed as far as all of the aforementioned comparisons were concerned.

\section{Results}

\section{Clinical data}

15 patients from the NW group completed the evaluation. 4 patients from the control group resigned during the course of the study. The reason for resignation was lack of consent for undergoing further control testing. Therefore, as far as statistical analysis, 26 patients who completed the study were taken into consideration.

According to the testing protocol, the pharmacological treatment of the patients was optimized and standardized in accordance with the current recommendations of the European Society of Cardiology (Table 1) [1].

\begin{tabular}{|c|c|c|}
\hline Medication & $\begin{array}{l}\text { NW group } \\
n=15\end{array}$ & $\begin{array}{l}\text { Control group } \\
n=11\end{array}$ \\
\hline $\mathrm{AT}_{1}$ Receptor antagonists (ARB) & 4 & 4 \\
\hline Calcium channel blockers & 5 & 1 \\
\hline$\beta$-adrenolytics & 11 & 6 \\
\hline $\begin{array}{l}\text { Converting enzyme inhibitors } \\
\text { (ACEI) }\end{array}$ & 12 & 7 \\
\hline Diuretics & 6 & 6 \\
\hline$\alpha_{1}$-adrenolytics & 2 & 1 \\
\hline
\end{tabular}

NW - Nordic walking; $n$ - number of evaluated patients.

During the course of the experiment, no side effects forcing the participants to abort NW training or to change the current pharmacological treatment protocol were observed. The study groups did not differ significantly as far as age and height was concerned (Table 2). Moreover, no significant differences between the groups were noted as far as body mass and BMI value, both before and after conducting the study (Table 2). However, a statistically significant reduction in body mass and the BMI value after finishing the 4-week training period was observed in the NW group, whereas in the control group, no significant changes regarding body mass and BMI were noted.

\begin{tabular}{|c|c|c|}
\hline Variable & NW group $(n=15)$ & Control group $(n=11)$ \\
\hline Age [years] & $56.7 \pm 5.8$ & $57.0 \pm 4.6$ \\
\hline Height [m] & $1.79 \pm 0.074$ & $1.76 \pm 0.079$ \\
\hline Body mass $1[\mathrm{~kg}]$ & $101.8 \pm 17.6$ & $97.2 \pm 14.7$ \\
\hline Body mass $2[\mathrm{~kg}]$ & $100.5 \pm 17.1^{*}$ & $97.2 \pm 15.0$ \\
\hline BMI $1\left[\mathrm{~kg} / \mathrm{m}^{2}\right]$ & $31.8 \pm 5.0$ & $31.2 \pm 4.2$ \\
\hline BMI $2\left[\mathrm{~kg} / \mathrm{m}^{2}\right]$ & $31.4 \pm 4.9^{*}$ & $31.1 \pm 4.2$ \\
\hline
\end{tabular}

NW - Nordic walking; 1 - pre-evaluation; 2 - post-evaluation; BMI - Body Mass Index; ${ }^{*} p<0.05$ in comparison with pre-evaluation values.

\section{Blood pressure values measured with the 24-hour AMBP test}

Median blood pressure values measured in the course of a 24-hour period, as well as daily and nightly blood pressure values of patients from both the NW group and the control group, are presented in Table 3.

No statistically significant differences were noted in median systolic blood pressure (SBP), diastolic blood pressure (DBP) and mean arterial pressure (MAP) during the 24 -hour period in both the NW group and control group patients both pre- and postexamination. Additionally, no statistically significant differences were observed as far as median SBP, DBP and MAP values between the respective groups are concerned. 


\begin{tabular}{|c|c|c|c|c|}
\hline \multicolumn{5}{|c|}{ Median 24-hour blood pressure values } \\
\hline \multirow[t]{2}{*}{ Variable } & \multicolumn{2}{|c|}{ NW group $(n=15)$} & \multicolumn{2}{|c|}{ Control group $(n=11)$} \\
\hline & Before & After & Before & After \\
\hline $\begin{array}{l}\text { SBP } \\
{[\mathrm{mm} \mathrm{Hg}]}\end{array}$ & $141.0 \pm 12.3$ & $137.0 \pm 10.8$ & $137.2 \pm 13.3$ & $134.2 \pm 11.3$ \\
\hline $\begin{array}{l}\text { DBP } \\
{[\mathrm{mm} \mathrm{Hg}]}\end{array}$ & $82.9 \pm 6.4$ & $80.3 \pm 6.8$ & $79.7 \pm 6.5$ & $78.2 \pm 5.4$ \\
\hline $\begin{array}{l}\text { MAP } \\
{[\mathrm{mm} \mathrm{Hg}]}\end{array}$ & $102.3 \pm 7.8$ & $99.2 \pm 7.7$ & $99.4 \pm 7.3$ & $96.9 \pm 7.1$ \\
\hline \multicolumn{5}{|c|}{ Median daily blood pressure values } \\
\hline $\begin{array}{l}\text { SBP } \\
{[\mathrm{mmHg}]}\end{array}$ & $145.1 \pm 11.8$ & $139.6 \pm 13.9$ & $138.5 \pm 11.9$ & $136.1 \pm 10.8$ \\
\hline $\begin{array}{l}\text { DBP } \\
{[\mathrm{mmHg}]}\end{array}$ & $85.4 \pm 6.2^{*}$ & $82.5 \pm 6.9$ & $79.8 \pm 5.8$ & $79.0 \pm 5.1$ \\
\hline $\begin{array}{l}\text { MAP } \\
{[\mathrm{mmHg}]}\end{array}$ & $105.3 \pm 7.3$ & $102.0 \pm 7.9$ & $99.3 \pm 7.2$ & $98.1 \pm 6.7$ \\
\hline \multicolumn{5}{|c|}{ Median nightly blood pressure values } \\
\hline $\begin{array}{l}\text { SBP } \\
{[\mathrm{mm} \mathrm{Hg}]}\end{array}$ & $127.0 \pm 16.9$ & $122.8 \pm 12.4$ & $133.6 \pm 17.7$ & $126.9 \pm 14.1$ \\
\hline $\begin{array}{l}\text { DBP } \\
{[\mathrm{mm} \mathrm{Hg}]}\end{array}$ & $74.1 \pm 9.9$ & $72.8 \pm 12.4$ & $77.9 \pm 7.7$ & $75.2 \pm 8.4$ \\
\hline $\begin{array}{l}\text { MAP } \\
{[\mathrm{mm} \mathrm{Hg}]}\end{array}$ & $91.8 \pm 11.8$ & $89.4 \pm 9.2$ & $95.8 \pm 10.8$ & $92.5 \pm 10.0$ \\
\hline
\end{tabular}

NW - Nordic walking; SBP - systolic blood pressure; DBP - diastolic blood pressure; MAP - mean arterial pressure; ${ }^{*} p<0.05$ in comparison with control group values.

Statistically significant greater daily median DBP values were noted in the NW group in comparison to the control group before evaluation. On the other hand, no statistically significant differences in mean DBP values were observed post-examination. Moreover, no statistically significant differences were noted in median daily SBP and MAP values between the groups both pre- and post-examination. Additionally, no significant changes were observed in median daily SBP and MAP values in relation to NW training.

No statistically significant differences were noted in median nightly SBP, DBP and MAP values between the study groups both pre- and post-evaluation. Furthermore, no statistically significant impact of the applied treatment on median nightly SBP, DBP and MAP values in both study groups was recorded.

\section{Exercise tolerance and laboratory testing}

Results depicting exercise tolerance evaluated in relation to time (T) and metabolic equivalent values (MET) with the use of an exercise tolerance test of patients with hypertension preand post-examination are presented in Table 4 . In both groups, statistically significant prolongation of the $T$ value during the exercise tolerance test was observed. Although the T values were greater in the NW group, the differences were statistically insignificant $(p=0.0776)$. On the other hand, the post-evaluation MET values were significantly greater only in the NW group.

The lab tests aimed at evaluating metabolic indicators, such as: total cholesterol, HDL, LDL and triglyceride levels. The results regarding the aforementioned metabolic factors in both groups of patients with hypertension pre- and post-examination are presented in Table 4. No statistically significant differences in median cholesterol, HDL, LDL and triglyceride levels between the groups pre- and post-examination were noted. However, a statistically significant reduction in total cholesterol and triglyceride levels post-examination in relation to the pre-examination stage was observed only in the NW group.

\begin{tabular}{|c|c|c|c|c|}
\hline \multirow[t]{2}{*}{ Variable } & \multicolumn{2}{|c|}{ NW group $(n=15)$} & \multicolumn{2}{|c|}{ Control group $(n=11)$} \\
\hline & Before & After & Before & After \\
\hline $\mathrm{T}[\mathrm{min}]$ & $10.4 \pm 2.8$ & $12.2 \pm 3.2^{*}$ & $9.1 \pm 2.8$ & $10.1 \pm 2.7^{*}$ \\
\hline $\begin{array}{l}\text { MET } \\
{[\mathrm{ml} / \mathrm{kg} / \mathrm{min}]}\end{array}$ & $13.3 \pm 3.0$ & $15.2 \pm 3.8^{* *}$ & $12.0 \pm 3.1$ & $12.4 \pm 3.4$ \\
\hline $\begin{array}{l}\text { T. Choles- } \\
\text { terol [mg\%] }\end{array}$ & $202.3 \pm 57.3$ & $181.5 \pm 50.2^{*}$ & $188.5 \pm 58.2$ & $178 \pm 42.3$ \\
\hline $\begin{array}{l}\text { LDL Choles- } \\
\text { terol [mg\%] }\end{array}$ & $118.4 \pm 38.3$ & $111.2 \pm 38.2$ & $109.9 \pm 55.0$ & $108.0 \pm 40.6$ \\
\hline $\begin{array}{l}\text { HDL Choles- } \\
\text { terol [mg\%] }\end{array}$ & $46.5 \pm 10.9$ & $42.9 \pm 11.2$ & $49.0 \pm 7.5$ & $46.0 \pm 8.7$ \\
\hline $\begin{array}{l}\text { Triglycerides } \\
\text { [mg\%] }\end{array}$ & $256 \pm 188.2$ & $\begin{array}{l}170.9 \pm \\
107.5^{* *}\end{array}$ & $158.1 \pm 54.8$ & $162.0 \pm 67.0$ \\
\hline
\end{tabular}

NW - Nordic walking; T - duration of exercise tolerance test on treadmill; MET - metabolic equivalent; T. Cholesterol - Total Cholesterol; ${ }^{*} p<0.05$ in comparison with pre-evaluation values; ${ }^{* *} p<0.01$ in comparison with pre-evaluation values.

\section{Discussion}

Epidemiological data demonstrating the reverse casualty between blood pressure values and physical activity level (questionnaires as a method of evaluation) or exercise tolerance (exercise test as a form of evaluation) proves the beneficial impact of physical exercise on blood pressure values. Moreover, middle-aged persons with high or average exercise tolerance demonstrated significantly lower resting blood pressure in comparison to persons with low exercise tolerance $[9,10]$.

It is to be accentuated that clinical data regarding the impact of physical training on blood pressure values was conducted on various groups of patients: normotensive and hypertensive, persons treated hypotensively and untreated, living a sedentary lifestyle or physically active, overweight, obese or of proper bodyweight, men and women, people of different racial backgrounds. The studies used various forms of aerobic physical training (bicycle cycloergometer, strolling/marching, jogging, dancing) or resistance training. The training sessions differed as far as workout duration and number of training sessions per week $[11,12]$.

It also needs to be emphasized that the results of laboratory tests in which various forms of physical activity in regards to daily, nightly and 24-hour period blood pressure values using the AMBP test were evaluated differ. Some of the results demonstrate that in patients with hypertension, median SBP and DBP values were lowered due to physical training [13-15]. On the other hand, in some cases, physical training did not provide the expected hypotensive effect in patients with hypertension [16-18].

Studies on the effects of physical training in patients with cardiovascular disease not receiving pharmacological therapy are rare [4-7].

The results achieved in the course of this study suggest that a protocol consisting of a 4-week period of NW training paired with optimized pharmacological treatment does not provide a statistically significant reduction of SBP, DBP and MAP values (daily, nightly and over the course of 24 hours) in overweight or obese male patients with hypertension.

By contrast, Latosik et al. [5] presented that an 8-week period of NW training resulted in a statistically significant reduction of SBP values in a group of 15 overweight menopausal women with systolic hypertension not treated pharmacologically. As far as DBP values are concerned, no reduction was found. Moreover, both SBP and DBP values pre- and post-workout did not differ substantially between the NW group and the control group $(n=9)$. 
A few factors may be responsible for the discrepancies between this study and the study conducted by Latosik et al. [5]. In the following study, changes in blood pressure values were evaluated using the 24-hour AMBP test and median daily, nightly and 24-hour SBP, DBP and MAP values in accordance with ESH/ /ESC standards (ESH/ESC Guidelines, 20130). In contrast, Latosik et al. [5] recorded only resting blood pressure values. What is more, the subjects of the following study were men with pharmacologically treated hypertension, whereas in the study conducted by Latosik et al. [5], the subjects were menopausal women with systolic hypertension not treated pharmacologically. Furthermore, different periods of NW workouts were applied -4 weeks in the following study, 8 weeks in the study conducted by Latosik et al. [5].

It is possible that methodological differences between the studies (divergent measurement methods, groups different as far as gender is concerned, NW workouts of different duration) affected the obtained results. However, the fact that pharmacological treatment of hypertension may have been a crucial factor cannot be dismissed. Therefore, it is possible that in patients not receiving pharmacological treatment, the hypotensive effect of physical activity is more "visible", whereas in persons treated pharmacologically, the effect may be "masked" by the effects of the treatment alone. However, in order to prove or disprove this hypothesis, further research is needed.

Another important factor as far as the effectiveness of hypertension treatment is concerned is the improvement of exercise tolerance [1]. The following study demonstrated that due to applying NW training in overweight or obese men with hypertension for a 4-week period, a statistically significant improvement in exercise tolerance (workout duration) and metabolic equivalent value during an exercise test using the Bruce's Protocol was achieved. In contrast, in the control group, the results were limited to exercise tolerance only. Exercise tolerance in the control group was insignificantly lower than in the NW group $(p=0.0776)$. The aforementioned data may suggest that the application of NW training in patients with pharmacologically treated hypertension contributes to improvement of exercise tolerance, which raises the patients' quality of life and is beneficial from a clinical standpoint.

Similar results proving the beneficial effect of NW training on exercise tolerance were observed in rare, heretofore, studies on patients with chronic heart failure [6, 7], post-acute coronary syndrome [4] or obese menopausal women [19].

The results achieved in the following study suggest that after the 4-week period of NW training, a statistically significant reduction in body mass and $\mathrm{BMI}$ occurred in patients from the NW group. On the other hand, no such effects were noted as far as the control group was concerned. The obtained data leads to the conclusion that NW training affects the aforementioned anthropometric indicators in patients with hypertension and thus lowers the risk of complications of cardiovascular disease [1].

It also needs accentuating that all the patients from the NW group completed the study, and no contraindications were noted during the course of the study. Therefore, a conclusion can be drawn that the application of NW training in patients with hypertension effectively treated with pharmacological means is safe. However, further research using cardiac telemonitoring is required in order to validate these findings.

\section{Conclusions}

The 4-week period of Nordic walking training did not result in the lowering of blood pressure in patients with hypertension. However, Nordic walking training resulted in improved exercise tolerance, decreased body mass, as well as reduced metabolic risk factors for cardiovascular disease, and was proven safe for patients with hypertension.

Source of funding: This work was funded by the Department of Physiotherapy at the Jerzy Kukuczka Academy of Physical Education in Katowice

Conflict of interest: The authors declare no conflict of interests.

\section{References}

1. The Task Force for the management of arterial hypertension of the European Society of Hypertension (ESH) and of the European Society of Cardiology (ESC). 2013 ESH/ESC Guidelines for management of arterial hypertension. Eur Heart J 2013; 34(28): 2159-2219.

2. Tschentscher M, Niederseer D, Niebauer J. Health benefits of Nordic walking. A systematic review. Am J Prev Med 2013; $44(1)$ : 76-84.

3. Rybicki JR, Leszczyńska-Bolewska BM, Grochulska WE, et al. Oxygen uptake Turing Nordic walking training in patients rehabilitated after coronary events. Kardiol Pol 2015; 73(1): 17-23.

4. Kocur P, Deskur-Śmielecka E, Wilk M, et al. Effects of Nordic Walking training on exercise capacity and fitness in men participating in early, short-term inpatient cardiac rehabilitation after an acute coronary syndrome: a controlled trial. Clin Rehabil 2009; 23(11): 995-1004.

5. Latosik E, Zubrzycki IZ, Ossowski Z, et al. Physiological responses associated with Nordic-walking training in systolic hypertensive postmenopausal women. J Hum Kinet 2014; 43: 185-190.

6. Kucio E, Mielczarek-Palacz A, Kucio M, et al. Wpływ treningu nordic walking na stężenie cytokin prozapalnych u pacjentów z przewlekłą niewydolnością serca. Rehabil Prakt 2011; 1: 25-29 (in Polish).

7. Piotrowicz E, Buchner T, Piotrowski W, et al. Influence of home-based telemonitored nordic walking training on autonomic nervous system balance in heart failure patients. Arch Med Sci 2015; 11(6): 1205-1212.

8. Fletcher GF, Baly GJ, Amsterdam EA, et al. Exercise standards for testing and training: a statement for healthcare professionals from the American Heart Association. Circulation 2001; 104(14): 1694-1740.

9. Reaven PD, Barrett-Connor E, Edelstein S. Relation between leisure-time physical activity and blood pressure in older women. Circulation 1991: 83(2): 559-565.

10. Kokkinos PF, Giannelou A, Manolis A, et al. Physical activity in prevention and management of high blood pressure. Hellenic $J$ Cardiol 2009; 50(1): 52-59.

11. Cardoso CG, Gomides RS, Queiroz AC, et al. Acute and chronic effects of aerobic and resistance exercise on ambulatory blood pressure. Clinics 2010; 65(3): 317-325.

12. Cornelissen VA, Smart NA. Exercise training for blood pressure: a systematic review and meta-analysis. J Am Heart Assoc 2013; 2: e004473, doi: 10.1161/JAHA.112.004473.

13. Moreira WD, Fuchs FD, Ribeiro JP, et al. The effects of two aerobic training intensities on ambulatory blood pressure in hypertensive patients: results of randomized trial. J Clin Epidemiol 1999; 52(7): 637-642.

14. Blumenthal JA, Sherwood A, Gullette EC, et al. Exercise and weight loss reduce blood pressure in men and women with mild hypertension: effects on cardiovascular, metabolic, and hemodynamic functioning. Arch Intern Med 2000; 160(13): 1947-1958.

15. Pinto A, Di Raimondo D, Tuttolomondo A, et al. Twenty-four hour ambulatory blood pressure monitoring to evaluate effects on blood pressure of physical activity in hypertensive patients. Clin J Sport Med 2006; 16(3): 238-243. 
16. Cooper AR, Moore LA, McKenna J, et al. What is the magnitude of blood pressure response to a programme of moderate intensity exercise? Randomised controlled trial among sedentary adults with unmedicated hypertension. Br J Gen Pract 2000; 50(461): 958-962.

17. Radaelli A, Piepoli M, Adamopoulos S, et al. Effects of mild physical activity, atenolol and the combination on ambulatory blood pressure in hypertensive subjects. J Hypertens 1992; 10(10): 1279-1282.

18. Seals DR, Reiling MJ. Effect of regular exercise on 24-hour arterial pressure in older hypertensive humans. Hypertension 1991; 18(5): 583-592.

19. Trabka B, Zubrzycki I, Ossowski Z, et al. Effect of a MAST exercise program on anthropometric parameters, physical fitness, and serum lipid levels in obese postmenopausal women. J Hum Kinetics 2013; 42: 149-155.

Tables: 4

Figures: 0

References: 19

Received: 03.07.2016

Revised: 15.07.2016

Accepted: 19.07.2016

Address for correspondence:

Cezary Kucio, MD, PhD, Assoc. Prof.

Wydział Fizjoterapii AWF

ul. Mikołowska 72A

40-065 Katowice

Polska

Tel.: +48 668 807-378

E-mail: cezary.kucio@gmail.com 